\title{
Uma bailarina pode ser negra? Crianças, bonecas e diferenças étnicas
}

\section{Ballerina is black? Childrens, dolls and ethnic differences}

\section{Michelle Brugnera Cruz Cechin*}

Universidade Federal do Rio Grande do Sul - UFRGS, Porto Alegre, Rio Grande do Sul, Brasil

\section{Thaise da Silva**}

Universidade Federal da Grande Dourados - UFGD, Vila Progresso, Mato Grosso do Sul, Brasil

\begin{abstract}
RESUMO
No presente artigo problematizam-se os modos como a construção de estereótipos e sentimentos preconceituosos são produzidos pelas imagens dos brinquedos, focalizando os bonecos e bonecas. Discute-se o modo como essas imagens estereotipadas produzem efeitos nas subjetividades infantis, analisando os discursos infantis sobre diferenças étnicas. Como método, utilizou-se uma abordagem qualitativa de análise do discurso. A pesquisa foi realizada em uma escola pública da rede municipal de ensino de Porto Alegre (RS). Participaram da proposta vinte e seis crianças, com idades entre sete e oito anos em dez encontros semanais, realizados de março a maio de 2011. Utilizou-se um pequeno acervo de quatorze bonecos e bonecas diferentes, que desconstroem estereótipos. Os resultados apontam que a imagem destas bonecas favorece a desconstrução de preconceitos e estereótipos.
\end{abstract}

Palavras-chave: infância, subjetivação, etnia, brinquedos.

\begin{abstract}
This paper discusses how the forms of stereotyping and prejudiced feelings are produced by focusing on the images of toys and dolls dolls. It discusses how these stereotypical effects on children's subjectivities, analyzing the discourses on childhood ethnic differences. As a method, used a planking qualitative discourse analysis. The research was conducted in a public school in the municipal schools of Porto Alegre (RS). Attended the proposed twenty six children, aged seven and eight in five weekly meetings, held from March to May 2011. We used a small collection of fourteen different dolls and puppets, they deconstruct stereotypes. The results show that the image of these dolls favors deconstruction of prejudices and stereotypes.
\end{abstract}

Keywords: childhood, subjectivity, ethinic, toy. 


\section{Crianças, bonecas e diferenças étnicas}

No presente trabalho problematizam-se os modos como a construção de estereótipos e sentimentos preconceituosos são produzidos pelas imagens dos brinquedos, focalizando os bonecos e bonecas. Discutese o modo como essas imagens estereotipadas produzem efeitos nas subjetividades, analisando os discursos infantis sobre diferenças étnicas. A fundamentação teórica é tecida principalmente por estudos que investigam os efeitos das imagens das bonecas nas subjetividades infantis (Brougère, 1998; 2002; 2004; Dornelles, 2003 e Souza, 2009) e pela sociologia da infância (Corsaro, 2002, 2003, 2005, 2011; Müller, 2007).

A pesquisa foi realizada em uma escola pública da rede municipal de ensino de Porto Alegre (RS), que atende fundamentalmente às classes sociais de nível socioeconômico baixo. Participaram da proposta 28 crianças, 16 meninos e 12 meninas, com idades entre 7 e 8 anos. Foram desenvolvidos 10 encontros semanais, realizados de março a maio de 2011. O principal objetivo da proposta foi compreender os discursos que são produzidos e tramados pelas crianças na sua relação com as bonecas, referentes às diferenças de etnia e características fenotípicas, promovendo atitudes de inclusão. Como método, utilizou-se uma abordagem qualitativa de análise do discurso e observações participantes.

Para a efetivação da proposta, foi composto um pequeno acervo de quatorze bonecos e bonecas diferentes, que desconstroem estereótipos. Ouviu-se as crianças e pesquisou-se, suas infâncias e suas relações com as bonecas. Analisou-se a dialética da cultura infantil, tecida por elas em suas relações e significações dos objetos e artefatos culturais. Cada encontro tinha uma dinâmica diferenciada, com vistas a possibilitar reflexões a cerca das bonecas. Os acontecimentos durante as brincadeiras e as conversas realizadas sobre o tema foram registrados minuciosamente através de um portfolio digital.

Descreve-se os discursos que emergiram das conversas, atitudes e interações nas brincadeiras, para entender como as crianças operavam tais conceitos. Narra-se também três cenas em que as diferenças étnicas tornam-se centrais para a continuação das brincadeiras. Buscou-se "dar voz" às crianças, vê-las como atores sociais, com uma postura ativa frente à cultura. Como as crianças estão imersas nas práticas sociais e delas são participantes, muitos desses valores e ensinamentos são reproduzidos em suas discursividades, em suas brincadeiras e representações. Contudo, além de reproduzir, as crianças interpretam os discursos imagéticos, a cultura na qual estão inseridas, imprimindo novas visões por meio de negociações e afiliações na cultura de pares (Corsaro, 2002, 2003, 2005, 2011; Müller, 2007). 
Desde a antiguidade, as bonecas fazem parte das diferentes culturas, refletindo as relações culturais, políticas e econômicas travadas nas sociedades, remetendo às diferentes formas em que foi organizada a vida das crianças. Historicamente, as bonecas fazem parte das brincadeiras infantis e representam o conceito que a sociedade tem da infância (Brougère, 2004; Bujes, 2004; Souza, 2009). O brinquedo participa da construção da infância através de complexos significados e práticas produzidas não apenas por seus criadores e difusores, como também por aqueles que o utilizam. É possível entender o lugar da criança na sociedade por meio dos usos e significados atribuídos aos brinquedos (Brougère, 2004).

Por serem portadoras de significados e valores culturais que revelam os discursos, concepções e representações da sociedade, os brinquedos revelam os conceitos de infância construídos historicamente pela cultura ocidental (Ariès, 2006). A cada momento histórico, forjam-se subjetividades próprias, pertencentes à cultura hegemônica consolidada. Na contemporaneidade, apenas um modelo de corpo estereotipado é mostrado através das bonecas ofertadas pelo comércio. A hegemonia de um modo de ser, de uma infância considerada ideal é produzida nas bonecas e brinquedos mesmo com - avanço nas problematizações da pluralidade cultural e inclusão social difundidos nos meios legislativos, acadêmicos e midiáticos (Brougère, 2004; Bujes, 2004; Souza, 2009).

$\mathrm{Na}$ produção industrial das bonecas, algumas características se sobrepõem a outras, produzindo ideias do que seja o normal e o patológico. Todas aquelas que não apresentam essas características são consideradas diferentes e, com oferta bastante reduzida, são difíceis de serem encontradas, são "menos normais". Conforme afirma Louro (2004): "Em nossa sociedade, devido à hegemonia branca, masculina, heterossexual, cristã, têm sido nomeados e nomeadas como diferentes aqueles e aquelas que não compartilham desses atributos" (pp. 49-50). Ao eleger uma estética corporal, uma raça, um gênero ou geração como "a melhor" se naturaliza e generaliza apenas um modo de subjetivação, e tudo o que é diferente se torna negativo. Isso ocorre também com a produção de bonecos e bonecas, que não devem estar fora da norma vigente.

Segundo Dornelles (2003), as subjetividades são formadas em um processo contínuo, fluido e inventado no transcurso de complexas histórias e vivências imbuídas de sentimentos de pertença, constituídos no interior de jogos de poder. As múltiplas subjetividades apresentadas pelos artefatos culturais, entre eles os brinquedos, produzem efeitos na constituição dos infantis. Os bonecos e bonecas podem parecer, a princípio, objetos inocentes destinados às crianças. Contudo, estão imersos nas relações de poder, apresentando discursos implícitos à sua materialidade do que é bom, agradável, normal e verdadeiro para a cultura hegemônica. As bonecas 
apresentam muito da cultura hegemônica e do padrão de beleza eurocêntrico: pele branca e olhos claros, corpo magro e cabelo liso e claro, o que ensina a supremacia de um corpo, raça e modo de ser (Dornelles, 2003).

Ao eleger uma estética corporal, uma raça, um gênero ou uma geração como "a melhor" se naturaliza e generaliza apenas um modo de subjetivação, e tudo o que é diferente se torna negativo. Isso ocorre também com a produção de bonecos e bonecas, que não devem estar fora da norma vigente. Para Dornelles (2003):

Algumas materialidades se sobrepõem a outras, produzindo certas 'normalidades', desse modo, é 'natural', no caso do uso de bonecos e bonecas, que os mesmos ao fazerem parte da sala de aula de crianças pequenas sejam da raça branca, com olhos azuis e longos cabelos loiros... Assim, tudo o que escapa ou se apresenta diferente deste 'modelo de normalidade', desta 'verdade' acerca da raça branca, é o 'diferente', o 'outro'. E este é o tipo de brinquedo consumido em série para crianças no que tange às 'diferenças' sejam elas raciais, de gênero, geração ou etnia. (p.4)

Tendo em vista que as bonecas são objetos de identificação e representação da normalidade, retratam uma determinada época e lugar através de marcas sociais que estão imersas em relações de poder. Tais marcas revestem-se de ricos significados culturais do ideal de beleza, de corpo e de sujeito. Ao elencar determinadas características como "as melhores", os corpos dos bonecos e bonecas fabricam modos de subjetivação que produzem "verdades" sobre como deve ser o corpo, o comportamento e as atitudes normais.

\section{Método}

A pesquisa foi desenvolvida em uma escola pública da rede municipal de ensino de Porto Alegre (RS), que atende, fundamentalmente, às classes sociais de nível socioeconômico baixo. Está localizada na periferia da cidade, sendo de difícil acesso através do transporte público urbano. É considerada de médio porte e atende aos nove anos do ensino fundamental. Participaram da proposta 28 crianças, 16 meninos e 12 meninas, com idades entre 7 e 8 anos. Foram desenvolvidos 10 encontros semanais, realizados de março a maio de 2011.

Para a efetivação da proposta, foi composto um acervo de quatorze bonecos e bonecas, que representassem certa diversidade: bonecas negras, de cabelo crespo, fadas e princesas africanas. Para transportar essas bonecas, foi confeccionada uma mala com gravuras 
de diferentes bonecas, inspirada nas antigas maletas em que vinham embaladas (Herlocher, 2009) e foi apresentada para as crianças como a "Mala Encantada de Bonecas" por conter bonecos e bonecas diferentes daqueles que costumavam brincar.

Os encontros com os bonecos e bonecas foram ministrados por uma das pesquisadoras, professora do grupo, e tinham como principal objetivo possibilitar que as crianças falassem de suas impressões. Cada encontro tinha uma dinâmica diferenciada, com vistas a possibilitar reflexões a cerca das bonecas: brincadeiras livres com as bonecas da mala; observação e registro dos comportamentos e diálogos durante a brincadeira das crianças; exploração das bonecas, solicitando que as crianças as separassem em diferentes grupos; roda de conversa para compreender a forma e o porquê as crianças separaram as bonecas daquela maneira; separação das crianças em grupos com algumas bonecas da mala; apresentação em grupo das suas impressões sobre as bonecas.

Os acontecimentos nas brincadeiras e as conversas realizadas sobre o tema foram registrados minuciosamente através de diário, fotos, gravações em áudio e vídeo. Buscou-se "dar voz" às crianças, vê-las como atores sociais, com uma postura ativa frente à cultura. Tal postura teórico-metodológica advém dos estudos da sociologia da infância (Corsaro, 2005; Delgado \& Müller, 2005), que trata as crianças como atores sociais, considerando os processos de releitura, reinvenção e reprodução realizados pelas crianças, conforme afirmam Delgado e Müller (2005):

A sociologia da infância estimula a compreensão das crianças como atores capazes de criar e modificar culturas, embora inseridas no mundo adulto. Se as crianças interagem no mundo adulto porque negociam, compartilham e criam culturas, necessitamos pensar em metodologias que realmente tenham como foco suas vozes, olhares, experiências e pontos de vista. (p. 353)

Como as crianças estão imersas nas práticas sociais e delas são participantes, muitos desses valores e ensinamentos são reproduzidos em suas discursividades, em suas brincadeiras e representações. Contudo, além de reproduzir, as crianças interpretam os discursos imagéticos, a cultura na qual estão inseridas, imprimindo novas visões por meios de negociações e afiliações na cultura de pares (Corsaro, 2002, 2003, 2005, 2011; Müller, 2007). Pesquisou-se e ouviu-se as crianças a respeito de suas infâncias e suas relações com as bonecas. Analisou-se a dialética da cultura infantil, tecidas por elas em suas relações e significações dos objetos e artefatos culturais. Posteriormente, a mala passou a fazer parte permanente dos momentos de brincadeiras na sala de aula. 


\section{Resultados e discussão: entre bailarinas étnicas e Barbies macumbeiras}

Nos encontros com os bonecos e bonecas, as crianças produziram diferentes discursos, ora de estranhamento, ora de discriminação e em outros momentos mostraram-se receptivas às diferenças representadas pelas bonecas. Os conceitos mais utilizados pelas crianças para classificar as bonecas foram os de beleza e feiura, bondade e maldade. Ao serem questionadas se era possível separar as bonecas em diferentes grupos, as crianças as separaram em dois grupos distintos: as bonecas legais e as outras bonecas.

Nas bonecas classificadas como as "Bonecas Legais" (figura 1), as crianças evidenciam o conceito de beleza da contemporaneidade. Falas como "Eu gostei do cabelo comprido e liso e da roupa", "Eu gostei dela porque tem esse cabelão e roupa de bailarina" mostraram que foram consideradas bonitas por seus cabelos lisos e por suas roupas. Neste caso, a cor da pele não foi um marcador importante de beleza, pois as bonecas estavam "bem vestidas", como ficou manifesto na fala das crianças ao olhar o corpo de uma boneca negra vestida de bailarina. 


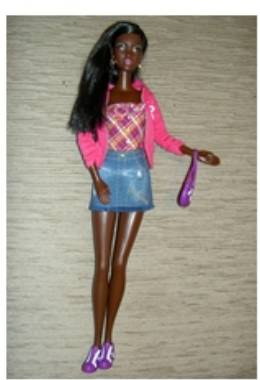

\begin{tabular}{|c|}
\hline Eu achei a \\
roupa dela bem \\
linda. Ela tem \\
uma sainha e \\
uma bolsinha. \\
(Menina de 6 \\
anos.) \\
Eu gostei do \\
cabelo \\
comprido e liso \\
e da roupa. \\
(Menino de 7 \\
anos.) \\
\\
É bonita porque \\
tem o cabelo \\
comprido a a \\
roupa é bonita. \\
(Menina de 6 \\
anos.) \\
\hline
\end{tabular}
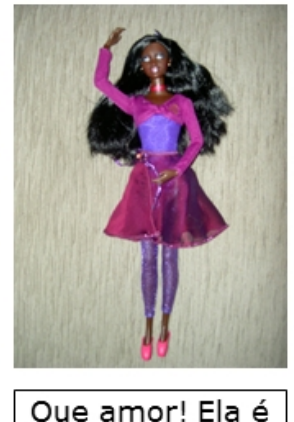
bailarina!

(Menina de 7 anos.)

Eu gostei dela porque tem esse cabelão e roupa de bailarina. (Menina de 7 anos.)

Eu achei bonita porque é bailarina.

(Menina de 7 anos.)

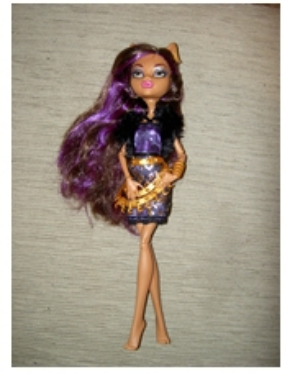

Ela é linda, tem o corpo bronzeado e o cabelo cumprido.

Eu achei ela bem bonita, e deve ser boa. Ela tem cara de boa. (Menina de 8 anos.)

Gostei dela. É uma lobisomen. É bem bonita.

(Menino de 7 anos.)

Lobisomem mata as pessoas.

(Menino de 7 anos.)

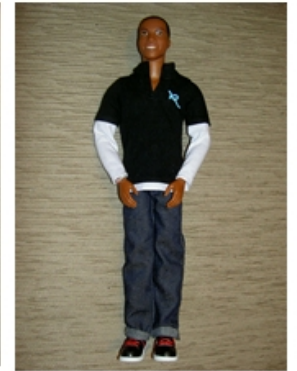

Ela é linda, tem o corpo bronzeado e o cabelo cumprido.

Eu achei ela bem bonita, e deve ser boa. Ela tem cara de boa.

(Menina de 8 anos.)

Gostei dela. É uma lobisomen.

É bem bonita.

(Menino de 7 anos.)

Lobisomem mata as pessoas.

(Menino de 7 anos.)

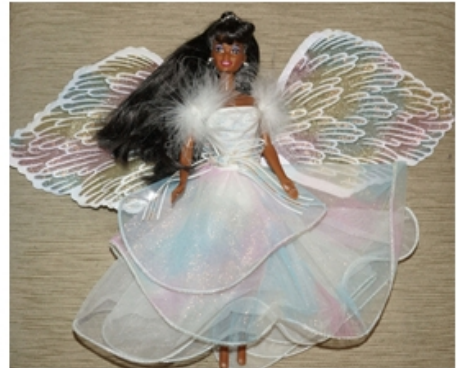

Ela é muito linda, tem o cabelo comprido e bem liso, o vestido brilhante. Ele é boa porque é uma fada e as fadas são boazinhas. (Menina de 7 anos).

Ele é bonita, porque tem um vestido rodado e com brilho, tem um cabelão. Acho que é boazinha, porque tem cara de boa, de amiga. (Menina de 7 anos).

É bem bonita. Nunca vi fada negra, mas é bonita e boazinha. (Menino de 8 anos.)

Achei bonita. Ela é boa porque tem o vestido branco de fada, ele tem brilho.

(Menina de 7 anos).

Figura 1 - Discursos sobre as "Bonecas Legais".

A Barbie Fada Negra causou certo estranhamento entre as crianças, que afirmaram nunca ter visto uma fada negra. Mesmo assim, todos a consideraram bela e boa, destacando seu cabelo liso, seu vestido branco e brilhoso. Os discursos referentes a esta boneca, mostram que as crianças podem pensar modos distintos de representar a bondade e beleza fora dos padrões vigentes das imagens a que estão imersas no cotidiano. Contudo, pode-se pensar também que a branquitude e luminosidade do vestido ao estilo das princesas clássicas possa ter "amenizado" o fato da boneca ser negra. Luz e trevas são representados como a antítese entre bem e mal, próprio dos preceitos medievais (Gomes, 2000).

No caso da boneca Lobisomem, apesar de ela representar uma monstra, tradicionalmente uma personagem vinculada ao mau, os discursos das crianças evidenciaram que sua beleza "atenuaria" a maldade, como na declaração "Gostei dela. É uma lobisomem. É bem bonita". Esta boneca faz parte da coleção Monster High, uma coleção de vinte e quatro bonecas que representam os filhos dos monstros tradicionais da literatura de terror. Se na tradição literária inglesa, o monstro é criado e destruído para promover o herói da trama, os 
monstros atuais simbolizam o alcoolismo, a ingestão de drogas, crueldade e assassinato que resultam dos processos de urbanização e avanço do capitalismo. Atualmente, os monstros assumem o papel principal de muitas tramas, sendo a vítima, ou o "lado bom da história" (Warner, 1999).

Na classificação “Outras Bonecas”, as crianças produziram discursos de discriminação, demonstrando o quanto estão imersas em preconceitos culturais (figura 2). A cor da pele e o tipo de cabelo foram tomados como marcadores de normalidade, em que o branco e o liso se sobrepõem ao negro e crespo. As falas "cabelo ruim" e "cabelo bagunçado" mostram um preconceito ao cabelo crespo.
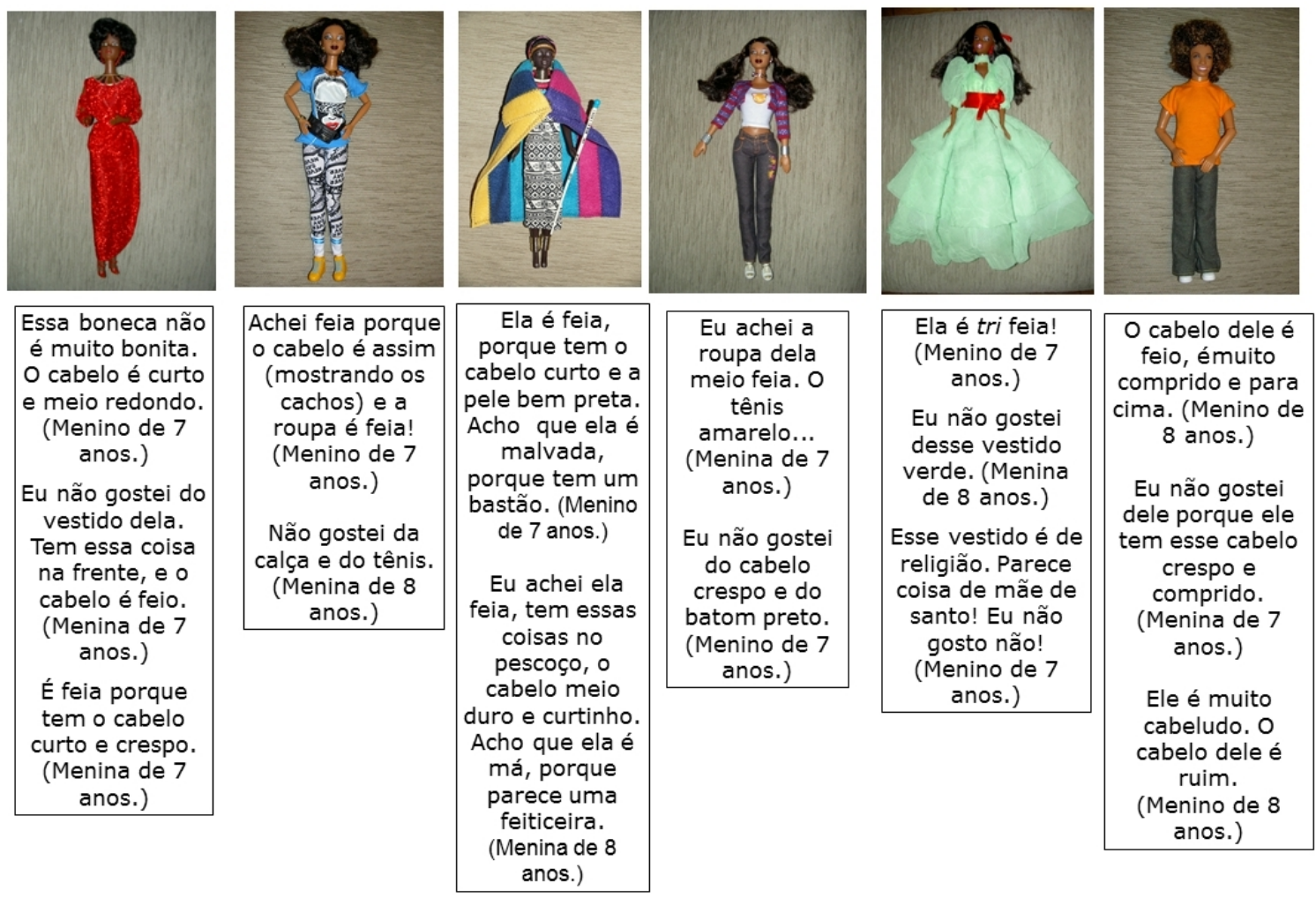

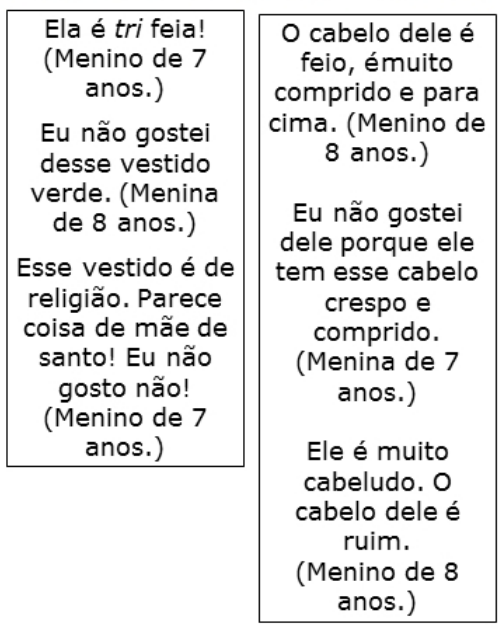

Figura 2 - Discursos sobre as "Outras Bonecas".

Ao se depararem com uma boneca que representa uma princesa negra africana, as crianças ficaram confusas, dizendo que não se parecia com uma princesa, pois sua pele era muito escura, o cabelo muito curto e as roupas feias, e em nada se parecia com as princesas com as quais estão acostumadas a ver ilustradas em livros e filmes (inscritas em um ideal de comportamento considerado nobre, além da branquitude da pele). Nos contos e filmes das princesas, as regras sociais da aristocracia são referendados, como a etiqueta da corte, os cuidados com o ambiente de convívio, o requinte da culinária a educação, a higiene do corpo. A etiqueta barroca instituiu regras disciplinares para rebuscar o corpo, ostentando poder através das vestimentas elaboradas, muitas jóias, maquiagem, sapatos de salto 
alto, perucas ornamentadas, bem como os gestos, as danças e os maneirismos. É o controle sobre o corpo, a postura e o comportamento requintado que define o status social dos sujeitos através de uma especularização dos corpos. Com a propagação da higiene, esta se torna um dos parâmetros para considerar alguém como culto e correto. A limpeza dos corpos, e o saneamento dos espaços, tornaram-se fundamentais para a prática do bem (Gomes, 2000; Hurley, 2005, Lacroix, 2004, Silverman, 2009; Wohlwend, 2008).

As princesas são imagens do bem, representadas por condutas virtuosas e comportamentos eleitos como os corretos. A bondade é expressa através da sua aparência que pode ser observada através de sua exibição, que garantiram o final feliz de suas histórias. Essas princesas ensinam que o modelo de beleza que apresentam expressa bondade e garante a "verdadeira felicidade" (Gomes, 2000; Hurley, 2005, Lacroix, 2004, Silverman, 2009; Wohlwend, 2008). Assim, ao estarem em contato com estas imagens, acredita-se que as crianças participantes do estudo se remeteram às imagens de princesas brancas, vestidas como a corte aristocrática européia, associando-as à bondade e candura que apresentam em suas narrativas e ao seu final feliz.

Nas falas referentes aos bonecos tipo Ken, emergiram discursos que mostraram como esse boneco não representa 0 ideal de masculinidade da cultura. Esses discursos mostraram o quanto as mídias em torno dos bonecos são diferentes. No lugar da palavra "boneco", os fabricantes usam o termo figuras de ação, que define os personagens como velozes, maldosos, heróis e viris vendidos aos meninos (Brougère, 2004; Roveri, 2008). As cores escolhidas pela publicidade para estampar as embalagens geralmente são mais escuras, os rostos com traços agressivos demonstram poder e seus membros são articulados para realizar inúmeros movimentos que simulam coragem e ousadia. Um dos representantes dessa modalidade de bonecos é o Max Steel, criado pela Mattel em 2000, para representar um "super-herói inteligente e forte na medida certa, modelo exemplar para crianças, um herói que luta incessantemente contra o mal. "Combinação única de fantasia e realidade", como é caracterizado pelo fabricante.

Connell (2005) descreve um conceito de masculinidade que prevalece na cultura ocidental: a masculinidade hegemônica, inclinada aos esportes, à competição, às ciências exatas, à racionalidade, e à identidade heterossexual. As demais representações da masculinidade, como sensível, artística, homossexual, bissexual, são chamadas masculinidades subalternas por estarem em patamares inferiores de poder em relação a formas hegemônicas de masculinidade, sendo alvo de exclusão, violência e ridicularização. Os bonecos produzidos para os meninos apresentam muito da forma 
masculina hegemônica e do padrão de beleza eurocêntrico: pele branca e cabelos claros, corpo musculoso, cabelo liso, rosto com expressão agressiva, denotando virilidade. Além disso, as características de beleza eurocêntricas são as formas vigentes apresentadas por esses bonecos. Os discursos apresentados neste estudo quanto ao Ken mostram um paradoxo de conceitos, sentimentos e atitudes frente aos diferentes modelos de masculinidade representados pelo boneco.

Das discursividades, brincadeiras e atitudes das crianças, destacamse três cenas em que a problematização de etnia e a transformação de atitudes foram centrais nas relações entre pares.

\section{Cena 1}

Três meninas, chamadas aqui de E., J. e N., brincam com bonecas Barbie e uma bolsa cheia de roupinhas. J. segura três Barbies na mão, uma negra vestida de bailarina, uma negra vestida com calça e blusa e uma loira vestida com biquíni. J. pergunta para N.:

J: - Qual delas tu achas mais bonita?

$\mathrm{N}$ : - Esta aqui. (Apontando para a Barbie negra vestida de bailarina.)

J: - Mas esta aqui tem o cabelo loiro e está de biquíni.

$\mathrm{N}$ : - Eu gostei mais dessa! Ela está com roupa de bailarina.

$\mathrm{J}$ : - Ela é negra. Nunca vi bailarina negra!

E: - Vamos tirar a roupa de bailarina dela e colocar nesta aqui. (Mostrando a Barbie praia.)

J: - Assim fica melhor!

A partir da cena exposta, pode-se compreender que, ao ofertar uma boneca Barbie negra, vestida de bailarina, na sala de aula de uma turma de segundo ano do ensino fundamental, uma das meninas afirma que ela não pode ser bailarina, pois é negra. A solução dada por outra menina é retirar a roupa de bailarina e colocar na Barbie praia, branca e com cabelos loiros (figura3). Esta cena indica o quanto as crianças estão sendo constantemente submetidas aos discursos de supremacia de um tipo de raça e corpo. Tanto em sala de aula como em casa, as crianças têm tido acesso apenas a um tipo de boneca, que apresenta um modelo de corpo, raça e etnia tido como "o normal", o "melhor". Para essas meninas, o "normal" é encontrarmos bailarinas brancas e não negras. A partir dessa "naturalização" do sujeito branco, loiro, magro e de olhos azuis, elencando-o como "o mais belo", tudo o que é diferente deste acaba se tornando o oposto, negativo, o diferente.

Uma das meninas questiona a outra, solicitando que apontasse a boneca mais bonita. Ao observar as brincadeiras com bonecas, vê-se que os conceitos mais utilizados pelas crianças para classificar as 
bonecas são os de beleza e feiura. Segundo Eco (2007), apesar de se conceber a feiura como oposto da beleza, as diversas manifestações do feio na história da humanidade são mais ricas e imprevisíveis, pois estão atreladas às culturas. "O feio é relativo aos tempos e às culturas; o inaceitável de ontem pode ser o bem aceito de amanhã e o que é percebido como feio pode contribuir, em um contexto adequado, para a beleza do conjunto" (Eco, 2007, p. 421). O que é percebido como belo em determinada época pode se tornar o inaceitável em outra.

A hegemonia das bonecas brancas e loiras tem tornado esse tipo de boneca o único que as crianças têm acesso em suas brincadeiras, fazendo com que as crianças "estranhem" as bonecas diferentes da tida como "a boneca normal". Alguns personagens vinculados pela mídia são divulgados como autoridades na autorregulação dos indivíduos. Nos discursos vinculados á boneca Barbie, que a descrevem como uma pessoa, os modos de ser menina são apreendidos como objeto passível de regulação e intervenção e governamento. As narrativas da Barbie tornaram-na uma expert da feminilidade, um modelo de corpo, de conduta, de beleza, de estilo e um modo de empreender cuidado sobre si. Pode-se dizer que a boneca Barbie é um objeto com identidade cultural, pois seu sucesso pode ser atribuído também às narrativas tramadas sobre ela em diferentes mídias, que construíram e renovaram suas diversas identidades, adequando-as à cultura de cada época.
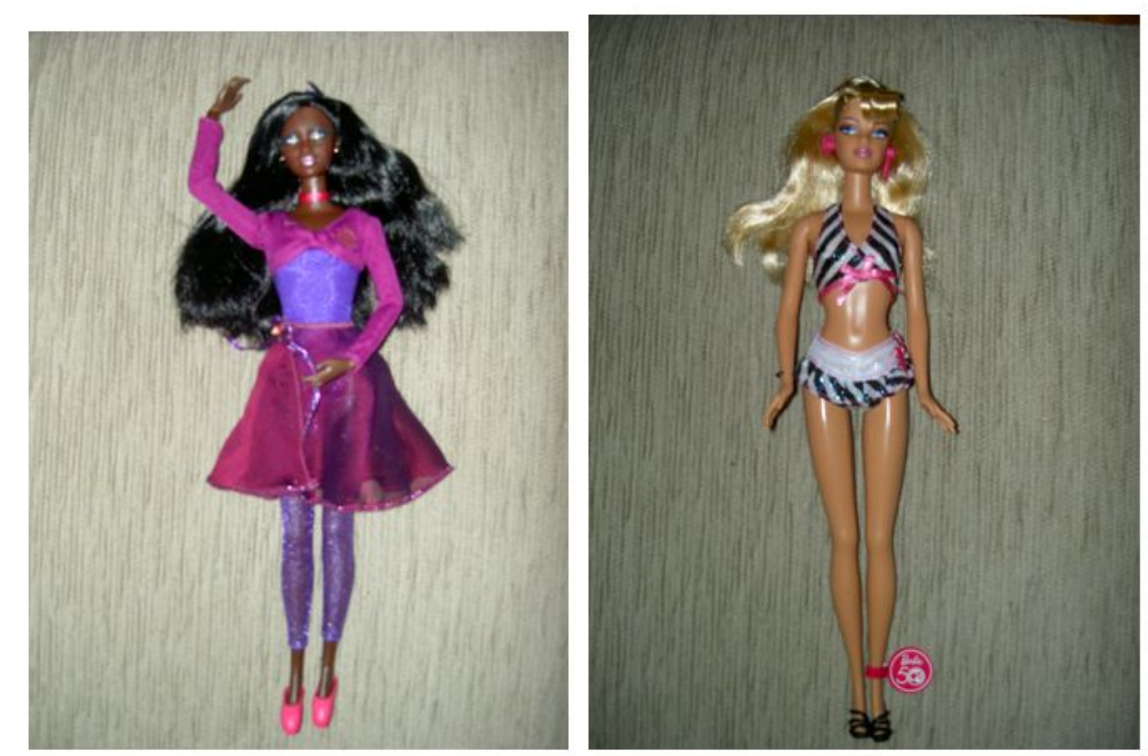

Figura 3 - Bonecas envolvidas na brincadeira descrita na cena 1.

Steinberg (2004) diz que a Barbie loira é o padrão a partir da qual as outras surgem. Apenas nas amigas da Barbie e em suas edições para colecionadores é que encontramos uma maior diversidade fenotípica. A primeira amiga negra da Barbie foi Christie, criada em 1968. Ao 
longo dos anos, muitas outras amigas negras foram produzidas. Contudo, elas apresentam as mesmas características da Barbie branca. A primeira Barbie negra foi lançada apenas em 1980, inscrita nos mesmos padrões norte-americanos de beleza e comportamentos juvenis legitimados em nossa cultura. As bonecas negras não significam apenas a democratização dos brinquedos ou uma problematização da diversidade, mas uma ampliação do mercado de bonecas, que procura atingir um número maior de meninas consumidoras. Como afirma Steinberg (2004),

O que está acontecendo aqui? A Mattel definiu etnia como diferente do branco. A Barbie normal, loira, é o padrão a partir do qual as "outras" surgem. Como emula a cultura dominante, a norma é a Barbie; sem um título, todas as outras Barbies são qualificadas por sua linguagem, alimentos e danças 'nativas'. Tentando ser multiculturais, pais compram essas bonecas para suas filhas para ensiná-las sobre "outros" povos (...). Barbie dividiu as bonecas dentro das culturas dominantes e marginais. A brancura da Barbie a privilegia a não ser questionada; ela é o padrão para todas as outras. (p.333)

O sucesso da boneca Barbie e sua permanência no mercado se devem também à representação de diferentes raças e etnias (Steinberg, 2004). As amigas da Barbie mostram que a emergência de bonecas negras não advém de uma preocupação em respeitar a diversidade, mas da expansão das vendas proporcionadas por essas novas bonecas. Reforçam a supremacia das características hegemônicas, uma vez que, seus corpos plásticos são apenas pintados de negro. As representações das características fenotípicas permanecem as mesmas: os longos cabelos lisos, o nariz fino, os lábios e a cor dos olhos (Schwarz, 2005; Terrenée, 2008). A boneca loira continua sendo o padrão de beleza na qual as outras são fabricadas.

\section{Cena 2}

Um menino, chamado neste texto de K., e uma menina, chamada de M., estavam brincando com duas Barbies, uma negra e outra branca, e um Ken loiro em uma casinha de bonecas. Após arrumarem as mobílias da casinha, preparando a brincadeira, K. diz para M.:

K: - Ele vai namorar com ela! (Apontando para a Barbie loira na mão de M.) M. responde:

M: - Ah, não! Essa é mais bonita! (Mostrando a Barbie negra.) Eu quero ser ela, e não a outra!

K: - Mas não tem um boneco negro aqui para namorar com ela. 
M: - Ela pode ser tua namorada.

$\mathrm{K}$ : - Mas o meu boneco é branco.

M: - E daí, não tem que ficar tudo igualzinho, ela pode namorar com o branco também!

Nesta cena, vemos que o menino não aceita que o boneco loiro namore uma boneca negra. A menina, que julga a Barbie negra como a mais bela, argumenta que "não tem que ficar tudo igualzinho", e conclui que a boneca negra pode namorar o boneco loiro (figura 4). Temos aqui uma relação entre pares, em que as crianças discutem o relacionamento entre sujeitos de diferentes etnias. Enquanto uma das crianças parece reconhecer a beleza da boneca negra e a possibilidade de os bonecos se relacionarem, o menino demonstra ter se apropriado de discursos preconceituosos. Essas múltiplas subjetividades apresentadas pelos artefatos culturais, como as bonecas, produzem efeitos na constituição dos sujeitos infantis. As crianças apresentam um paradoxo de sentimentos e atitudes frente ao respeito à etnia ou raça, mostrando-se preconceituosas, e em outros momentos solidárias, afetivas e corteses.
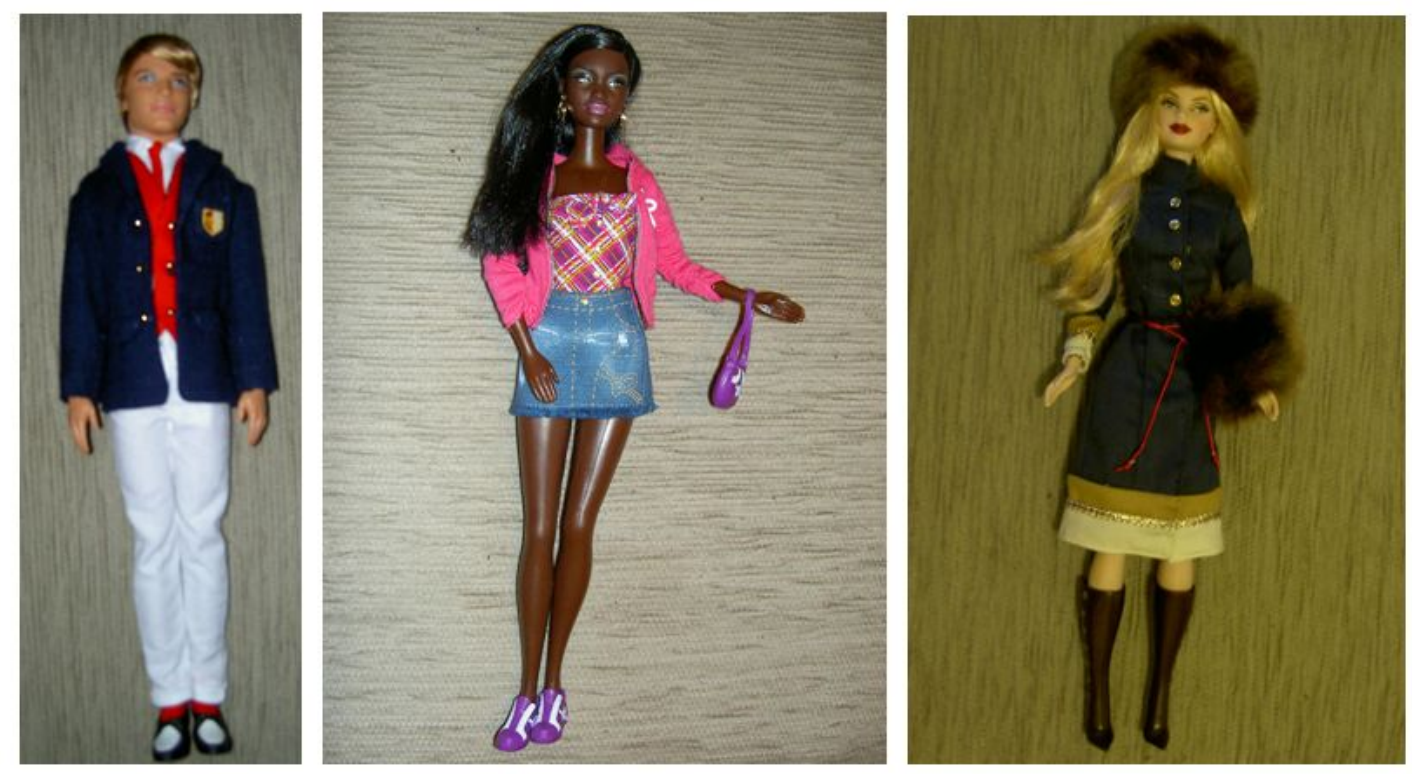

Figura 4 - Boneco e bonecas envolvidos na brincadeira descrita na cena 2.

Essa cena exemplifica o modo como as subjetividades são produzidas nos jogos de poder de nossa cultura. As diferenças precisam ser compreendidas para além do discurso da tolerância com a diversidade cultural, tendo em vista que as diferenças não existem em si, são produzidas no interior das malhas do poder, tramadas através das políticas, das leis, das mídias, dos discursos, que existem independentemente de serem ou não aceitas. 
É fundamental analisar e compreender como operam os dispositivos das diferenças étnicas, o corpo de saberes, sobre o sujeito negro infantil e investigar como o sujeito negro está sendo produzido nas articulações entre poder e saber.

\section{Cena 3}

Em uma manhã fria e chuvosa, apenas quatro meninos estavam presentes na aula. Devido às intempéries do tempo, que dificultava a chegada à escola, muitas das crianças não puderam comparecer naquele dia. Os quatro "guerreiros" não se mostraram desanimados ou apáticos, mas, pelo contrário, estavam ávidos por brincar e fazer coisas que não poderiam caso mais colegas estivessem presentes em aula. Eis que um deles me solicitou os brinquedos que estavam guardados no armário. Em meio a carrinhos, jogos, e alguns Max Steel, um dos meninos, não satisfeito com o que lhe era oferecido, diz: - Profe, pega aquelas tuas Barbies negras! E pega aquela Barbie macumbeira também! - apontando para uma boneca ruiva vestida de vermelho que estava em uma prateleira alta do armário.

Chamavam de "Barbie macumbeira" uma edição especial da boneca Barbie em homenagem à cantora Cindy Lauper (figura 5). O termo "macumbeira" é o adjetivo da palavra macumba que, segundo o dicionário Houaiss (2009), é uma "designação leiga dos cultos afrodescendentes em geral (e seus ritos respectivos)" (p. 477).

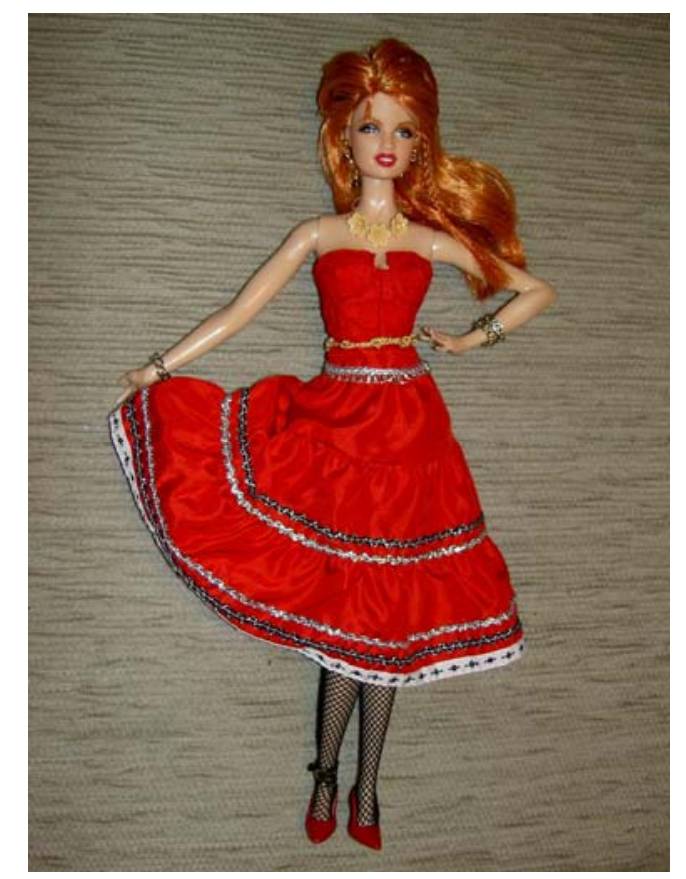

Figura 5 - Boneca descrita na cena 3.

Ao entregar-Ihes as bonecas, foi armada a brincadeira: as Barbies negras namoraram os Max Steel, que ao invés de serem 
protagonistas de lutas, se tornaram pais, irmãos, filhos. A "Barbie macumbeira" fez um ritual dos "quatro pés", típico de algumas religiões afrodescendentes, e depois se tornou uma cabeleireira. Aquele quarteto que outrora afirmava que brincar com bonecas era "coisa de bichinha", se entregara para o "encanto" das Barbies negras. Dessa forma, apesar dessa boneca representar um corpo branco, suas vestimentas e características fizeram essa criança lembrar-se dos cultos das religiões afrodescendentes, o que, para ele, se mostrou agradável. Ao terem a oportunidade de brincar com bonecas diferentes, que fogem ao estilo imposto pelas normas vigentes, as crianças constroem modos-artistas de brincar. A produção de um novo modo de brincar, de ver as bonecas e de recriar a cultura possibilita a resistência às subjetividades impostas, possibilitando a formação de sujeitos mais generosos e menos preconceituosos.

\section{Considerações finais}

Com este trabalho, procurou-se compreender quais discursos seriam tramados pelas crianças ao se depararem com essas bonecas que desconstroem alguns estereótipos difundidos através das bonecas na cultura contemporânea. Pelos resultados, viu-se que os múltiplos modelos de subjetividades apresentados pela cultura através dos artefatos culturais voltados para a infância produzem efeitos no desenvolvimento das crianças, que passam a utilizá-los como referência. Salienta-se a importância de replicar estudos como este em pesquisas de maior amplitude, pois somente um conjunto de evidências com grupos maiores de crianças pode confirmar a eficácia de tal tipo de estudo.

Os discursos apresentados neste estudo mostraram um paradoxo de conceitos, sentimentos e atitudes frente às diferenças. Em alguns momentos, as crianças se mostraram espantadas com algumas alteridades, em outros, se mostraram racistas ou solidárias e afetivas. Essa diversidade nos discursos infantis denuncia o modo que as múltiplas subjetividades são tramadas nas relações de poder. Os múltiplos modelos de subjetividades apresentados pela cultura através dos artefatos culturais voltados para a infância produzem efeitos no desenvolvimento das crianças, e elas os reproduzem e elaboram por meio das brincadeiras.

Apesar do desenvolvimento crescente das novas tecnologias do brincar, as crianças continuarão a significá-lo e se constituir através dele, pois são capazes de subverter a ordem, escapar aos condicionamentos e imprimir originalidade em seu brincar, conforme diz Dornelles (2001): 
A criança expressa-se pelo ato lúdico e é através desse ato que a infância carrega consigo as brincadeiras. Elas perpetuam e renovam a cultura infantil, desenvolvendo formas de convivência social modificando-se e recebendo novos conteúdos, a fim de renovar a cada nova geração. (p. 103)

Corsaro (2005) defende que as crianças compartilham, negociam e criam cultura junto com seus pares e com os adultos através de uma reprodução interpretativa. Segundo o autor, a estrutura social está constantemente impondo a internalização de valores e regras sociais por meio de diferentes práticas. No entanto, as crianças contribuem ativamente para a produção e a mudança cultural, reproduzindo a cultura a partir da sua interpretação inovadora e criativa, preservando e, ao mesmo tempo, transformando a sociedade.

A presente experiência mostra que, mesmo conduzidas pela publicidade dos brinquedos para orientar as brincadeiras com as bonecas, as crianças podem dar asas à sua imaginação, pois demonstraram que existem inúmeras formas de desvios do uso das bonecas. Se qualquer objeto pode se tornar um brinquedo, qualquer brinquedo também pode ser usurpado. Apesar do apelo comercial e publicitário vinculado aos brinquedos, as crianças continuarão mostrando construções novas, resistências e novas possibilidades de ser sujeito infantil na contemporaneidade.

\section{Referências}

Ariès, P. (2006). História Social da Criança e da Família. Rio de Janeiro: LTC.

Brougère, G. (1998). Brinquedo e Educação. Porto Alegre: Artmed.

Brougère, G. (2002). Brinquedo e Cultura. São Paulo: Cortez.

Brougère, G. (2004). Brinquedos e Companhia. São Paulo: Cortez.

Bujes, M. I. (2004). Criança e Brinquedo: feitos um para o outro? In M. V. Costa (Org.), Estudos Culturais em Educação: mídia, arquitetura, brinquedo, biologia, literatura, cinema... Porto Alegre: Editora da UFRGS.

Connell, R. W. (2005). Masculinities. California: California II.

Corsaro, W. A. (2002). A Reprodução Interpretativa no Brincar ao "faz-de-conta" das crianças. Educação, Sociedade \& Culturas, (17), 113-134.

Corsaro, W. A. (2003). We're Friends, Right? Inside Kid's culture. Washington: J oseph Henry Press.

Corsaro, W. A. (2005). Entrada no Campo, Aceitação e Natureza da Participação nos Estudos Etnográficos com Crianças Pequenas. Educação e Sociedade, 26(91), 443-464. 
Corsaro, W. A. (2011). The Sociology of Childhood. Indiana University: Pine Forge Press.

Delgado, A. C. C. \& Müller, F. (2005). Sociologia da Infância: pesquisa com crianças. Revista Educação e Sociedade. 26(91), p. 351-360.

Dornelles, L. V. (2001). Na escola infantil todo mundo brinca se você brinca. In G. E. Kaercher \& C. M. Craidy (Orgs.) Educação Infantil: pra que te quero? Porto Alegre: Artmed.

Dornelles, L. V. (2003). O brinquedo e a Produção do Sujeito Infantil. Centro de Documentação e Informação sobre a Criança. Universidade do Minho. Instituto de Estudos da Criança. Recuperado em 03 de dezembro, 2010, de http://cedic.iec.uminho.pt/Textos_de_Trabalho/textos/obrinque do.pdf

Eco, U. (2007). História da Feiúra. Rio de Janeiro: Record.

Gomes, P. B. M. B. (2000). Princesas: Produção de subjetividade feminina no imaginário de consumo. Dissertação de Mestrado, Faculdade de Educação, Universidade Federal do Rio Grande do Sul, Porto Alegre.

Herlocher, D. (2009). 200 Years of Dolls. Krause Publications.

Houaiss, A. (2009). Minidicionário Houaiss da Língua Portuguesa. Rio de Janeiro: Objetiva.

Hurley, D. L. (2005). Seeing White: Children of Color and the Disney Fairy Tale Princess. The J ournal of Negro Education, 74(3), 221.

Lacroix, C. (2004). Images of animated others: The orientalization of Disney's Cartoon Heroines from the little mermaid to the hunchback of Notre Dame. Department of Communication. College of Charleston. Geori-e Street. Charleston.

Louro, G. L. (2004) Um corpo estranho: ensaios sobre sexualidade e teoria queer. Belo Horizonte: Autêntica.

Müller, F. (2007) Entrevista com William Corsaro. Educação e Sociedade, 28(98), p. 271-278.

Roveri, F. T. (2008). Barbie - Tudo o que você quer ser... ou considerações sobre a educação de meninas. Dissertação de Mestrado, Faculdade de Educação, Universidade Estadual de Campinas, Campinas.

Silverman, R. A. (2009). New Dreams, Old Endings: Searching for "A Whole New World" in Disney Second-Wave Animated Romance Films. Faculty of Wesleyan University. Departmental Honors in Sociology.

Souza, F. M (2009). Revirando Malas: entre histórias de bonecas e crianças. Dissertação de mestrado, Universidade Federal do Rio Grande do Sul, Porto Alegre.

Schwarz, M. T. (2005). Native American Barbie: The Marketing of Euro-American Desires. American Studies, 46, p. 295-326. 
Steinberg, S. R. (2004). A mimada que tem tudo. In S. R. Steinberg \& J. L. Kincheloe (Orgs.). Cultura Infantil: a construção corporativa da infância. Rio de Janeiro: Civilização Brasileira.

Terrenée, R.(2008). Fulla, the veiled Barbie: An analysis of cultural imperialism and agency. MAI Review, 2, Santa Cruz Report.

Warner, M. (1999) Da Fera à Loira: sobre contos de fadas e seus narradores. São Paulo: Companhia das Letras.

Wohlwend, K. E. (2008). Damsels in Discourse: Girls Consuming and Producing Identity Texts Through Disney Princess Play Reading. Research Quarterly, 44(1), 57-83.

\section{Endereço para correspondência \\ Michelle Brugnera Cruz Cechin}

Prefeitura Municipal de Porto Alegre

Escola Municipal de Ensino Fundamental América.

Rua Padre Ângelo Costa, 175, Partenn, CEP 91520-160, Porto Alegre - RS, Brasil

Endereço eletrônico: mibrugnera@gmail.com

\section{Thaise da Silva}

Prefeitura Municipal de Porto Alegre

Secretaria Municipal de Educação de Porto Alegre

Rua Saul Constantino, 100, São José, CEP 91560-450, Porto Alegre - RS, Brasil

Endereço eletrônico: thaiseds@ibest.com.br

Recebido em: 05/12/2011

Reformulado em: 27/01/2014

Aceito para publicação em: 02/02/2014

\section{Notas}

* Especialista em Psicopedagogia Institucional e Clínica (FAPA). Licenciada em Pedagogia (FAPA). Mestranda em Ciências Médicas: Psiquiatria na Universidade Federal do Rio Grande do Sul (UFRGS). Professora da rede municipal de ensino de Porto Alegre.

** Doutora em Educação (UFRGS). Mestre em Educação (UFRGS). Especialista em Alfabetização (FAPA). Professora adjunta da Universidade Federal da Grande Dourados, UFGD. 